\title{
Extra-Ordinary Solutions for Useful Smart Living
}

\author{
Elisabetta Ginelli, Claudio Chesi, Gianluca Pozzi, Giuditta Lazzati, \\ Davide Pirillo and Giulia Vignati
}

\begin{abstract}
The project 'cHOMgenius. PrototipeSystem and SharedProject. Soluzioni straordinarie per l'abitare intelligente' studies a modular constructional system and experiments with design solutions, examining constructive, structural and plant engineering techniques for OFF-GRID dwellings featuring home automation control and managed by digital tools with relevant verification and monitoring instruments, in a logic of complete disassembly, reuse and recycling according to the most recent European directive. This project, which includes as partners two Lombard companies together with the Politecnico di Milano, is supported by 20 national and international companies and by the UNI 'Ente Italiano di Normazione'. The OFF-GRID prototype consists of entirely 'clamping' technical-constructive solutions, digital management/energetic solutions, innovative maintainability solutions for seismic safety and economic sustainability, in relation to the high-energetic performance offered and the technical solutions adopted. cHOMgenius is a shipping container building totally placing itself within the circular economy, through the reuse of $\mathrm{HC} 20^{\prime}$ and $40^{\prime}$ containers made of corten steel as supporting structure of the dwelling. The approach to the theme of circular economy pursued is intrinsically linked to the 3Rs concept, understood as: (i) reduction of material in terms of quantity, embodied energy and time, resulting in a better use of products and giving them a multi-functionality character; (ii) recycling of products and materials through the use of dry technologies, offering the option to use decoupling materials in order to avoid not only dismantling costs, often uneconomical, but also to avoid polluting industrial cycles due to recycling; (iii) reuse/reapplication, seen as the most evident plus of the circular chain as it is considered synonymous with the increase of products' life.
\end{abstract}

Keywords Accomplished project - Industrialization - Useful life cycle costs • Experimentation sharing $\cdot$ Evolutionary process $\cdot$ Recombining innovation • Prediction

E. Ginelli $(\varangle) \cdot$ C. Chesi · G. Pozzi · G. Lazzati · D. Pirillo · G. Vignati

Architecture, Built Environment and Construction Engineering-ABC Department,

Politecnico di Milano, Milan, Italy

e-mail: elisabetta.ginelli@polimi.it 


\section{Introduction}

This paper shows a project funded by the 'Smart Living' call promoted by Regione Lombardia, which supports development and innovation projects carried out by partnerships in the construction, wood home furniture, appliance and high-tech sectors in collaboration with the universities, implementing the Regional Law 26/2015 'Manifattura diffusa, creativa e tecnologia 4.0' ('Creative and common manufacture and Technology 4.0') and developing the "LOMBARDIA 5.0" strategy. The aim is to address the evolutionary dynamics of productive sectors and especially to favour the qualification of the economic system through the stabilization and enhancement of 'excellent supply chains' as development drivers.

Timeline:

- February 2017 open call

- June 2018 starting date of the project—design phase

- July 2019 realization of the mock-up

- September 2019 monitoring phase

- December 2019 end of project.

\section{Cultural Framework}

On an institutional level, the construction sector and that of production, in general, have to act within a scenario marked by environmental issues, which must sensitize the designing and fulfilment actions of building interventions.

The proposal here illustrated is placed in such context and is representative of a design process, chiefly aiming at enhancing the energy used throughout the life cycle (Adalberth 1997) of a single-family residential building with a permanent residential function.

The project is based on the research and development of an industrial modular building system model (Kotnik 2008; Kramer 2015) offering high-energy performances (OFF-GRID) but also entailing current market costs. It proposes the construction of a residential prototype, based on industrialization, recycling and the eco-efficiency of natural, productive and professional resources criteria.

It focuses on the principles of hybridization and contamination between different productive sectors which, upon reaching shared objectives and results, translate into fruitful carriers of renewal and economic potentiality, for the purpose of contributing to a revival of the construction sector according to a proactive interpretation of the sustainability rules (environmental, social, economic and institutional). 
The reference scenario related to sustainability is defined by the UNI 11277 standard and by the UNI PdR $13^{1}$ and its integration with CAM, ${ }^{2}$ the relationship between energy saving and comfort, and the awareness in the use of resources provided by the principle of the 3Rs (reduction, reuse, recycling) (Huanga et al. 2018; Islam et al. 2016).

In a nutshell, the guideline of the study is based on the desire to innovate residential production by harnessing 'transfer' products as well as multifunctional solutions and products (i.e. products with multiple functions), combining the existing production know-how with advanced technologies to provide a 'system/product' in use with no $\mathrm{CO}_{2}$ production.

\section{Tools and Methods}

The aforementioned programmatic scenario influences the method and choice of the tools applied in this study, within the cultural sphere of technological and environmental architecture design.

The approach we intend to pursue is meta-planning and is meant to provide guidelines. The immaterial invariants of the project determine the established performance for the resulting design and can be summarized as follows: time variable management: quick building times, rapid response times to external system stimuli, rapid dismantling and reuse or swift recycling times; transferability: the solutions (technotypological, morphological, structural, plant-related) must be transferable in other geographical and demanding contexts; design and production innovation: transfer and/or adaptation from sectors dealing with the current manufacture of products, techniques and knowledge, building practice and other fields; qualitative multifunctionality of the architectural system, understood as the possibility to use in multifunctional terms both the whole system and the individual components, where the latter establish multifunctional relations for maximizing the use of the system potentiality; constructive reactive system: from a structural point of view (active anti-earthquake systems), from an energy point of view (integrated building/plant management) and from a technical point of view, in relation to the entire life cycle of the building and its components.

The invariants, in turn, have been translated into technological and functional resource requirements and objects, due to their strong circularity in the use and reuse of the involved resources and because they give substance to the concept of 'active resilience' of the project, read as the regeneration capacity of its intrinsic value

\footnotetext{
${ }^{1}$ UNI/PdR 13.1:2015 Sostenibilità ambientale nelle costruzioni-Strumenti operativi per la valutazione della sostenibilità (Environmental sustainability in buildings-Operative tools for sustainability assessment).

${ }^{2}$ DECRETO 11 ottobre 2017. Criteri ambientali minimi per l'affidamento di servizi di progettazione e lavori per la nuova costruzione, ristrutturazione e manutenzione di edifici pubblici (Minimum environment criteria for the allocation of design services and works related to the new construction, restructuring and maintainance of public buildings).
} 
Table 1 Main resilience requirements for the project, as keywords

\begin{tabular}{l|l}
\hline Resilience requirements for the project \\
\hline Technological-functional requirements & Examples of object requirements \\
\hline Flexibility (Ginelli 2010) & Convertibility (Bologna 2002) \\
\hline Predictive and adaptive project & Smart object \\
\hline Reactive project & Durability (Jourda 2010), re-functionalization \\
\hline Redundancy of systems & Multi-functionality reliability fault-tolerant design \\
\hline Replicability & $\begin{array}{l}\text { Industrialization and prefabrication (Ginelli and Pozzi } \\
\text { 2017) }\end{array}$ \\
\hline Sharing & Communication guarantee \\
\hline Technological flexibility & $\begin{array}{l}\text { Accessibility, maintainability, substitutability and } \\
\text { transformability }\end{array}$ \\
\hline
\end{tabular}

(Ginelli and Pozzi 2017). The greater the intrinsic capacity of a building to accept changes and modifications to achieve a new given performance picture, the lower the cost of this upgrading and thus the greater its active resilience.

The same applies to embodied energy: the project has the intrinsic capacity to make energy available for time $t(0+x)$-a time in future-whose conditions are still unknown, but which mandatorily require the right strategy (active resilience) to afford changes.

This active resilience generates invariants and requirements for the project. Such requirements are a priori strategies valid for each project and can be used so that the building, regardless of individual materials and specific products, can be resilient and thus actively respond to physiological changes or unforeseen events.

These requirements are attributed to the project in its general aspects, constitute the cultural approach that is essential to the project and originate techno-functional conditions. Each of them has been associated with prerequisites that objects must have, thus, giving rise to object requirements which are consequently related to the building material components and play a specific role in the logic of an active resilience project (Table 1).

Another important concept the project has been pursuing is 'recombining innovation'. It is defined as the capacity to create value by connecting products and know-how in a smart way, since this project could create the right conditions for companies and designers to produce 'better' ideas and outputs thanks to the network they establish with others (Fig. 1).

\section{Results: The Project}

Before proceeding with the specific description of the system, we wish to highlight some tenets regarding the design of the dwelling, divided into the different phases of the construction's life cycle: 


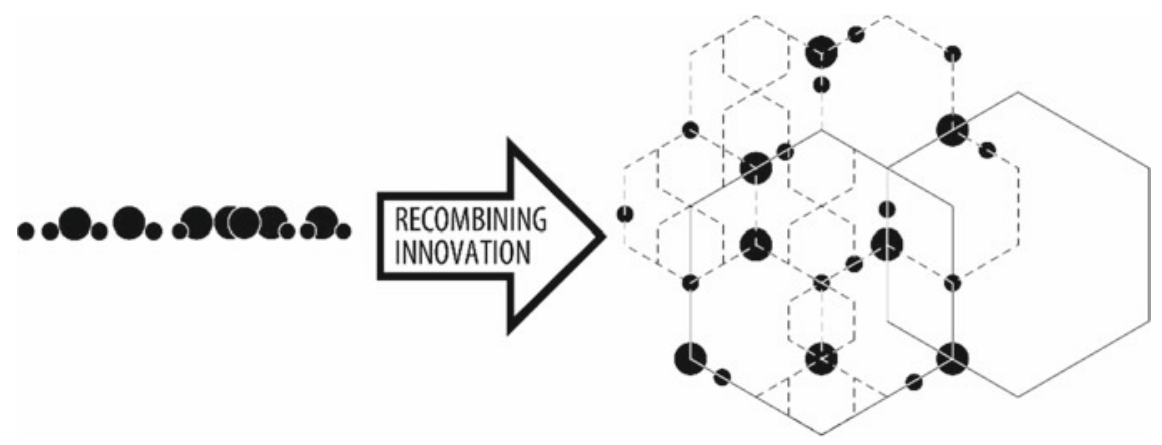

Fig. 1 Added value that recombining innovation can give to products, creating positive networks

1. Construction of the building and its components: dry technology with 'tightening' techniques (Giordano 2010); use of shipping containers as a structural system of the building organism and casing structure; use of a screw foundation system that guarantees the reversibility of the ground condition by dismantling; use of elements already pre-assembled in workshop, including counter frames, window frames, systems, fixed equipment, etc., use of prefabricated elements, such as prefab bathroom, staircase; minimum work on-site: assembly of coatings, some 'fragile' components, connections, etc., reuse of part of the container's removed metal sheet to be reinserted in the building for other purposes;

2. Management of the building and its components: independence from electric and gas networks (OFF-GRID); minimization of thermal losses; simplified system management: simplified interface for end users; self-learning of electromechanical equipment (from climate management to small household appliances); system performance and technological adaptability: system tested for different climatic area, from the Mediterranean to the continental one; substitutability of structural joints: in the event of an earthquake the only possible deformations are concentrated in the joints between the containers, which are monitored by specific sensors; therefore, it is possible to highlight the damaged joints and easily replace them;

3. 'End of life' of the main function, which stands for the convertibility of the system: reuse of the container module: the basic structure can be reused without heavy interventions; component multi-functionality: the structure of the container performs both structural and closing functions, while providing a considerable mass for thermal inertia; expandability: the structural module does not correspond to the living cell, meaning that it can be used for infinite compositions; possible new reconfiguration of the system: the easy disassembly and reassembly of the joints ensures an easy and quick reconfiguration of the structural modules; module transformability: the structural module can be used in different configurations, some of which require minimal interventions; module durability: the structural module is in corten steel, which is guaranteed to resist extreme conditions, including saltiness; energy recovered at the end of the function: all the 
employed corten steel, which has high levels of embodied energy, can be used without additional energy for other functions (the structural module can become something else without other processes);

4. End of building life (Faludi et al. 2012): reversibility of the foundation system: once unscrewed the screw foundations, the ground returns to its original state without any damage; disassembly of the components: all connections are made with clamping and thus easily separable systems; reuse of the container: the basic structure can be reused without heavy interventions; reuse of the casing components: both the finishes and the thermal insulation are mechanically fixed, so that they can be easily dismantled and reused; recycling of container components: as a last opportunity, the container is made of corten steel which can be used as a second raw material;

5. 'End of life' of the main function. Transformation of its component parts: disassembly of the components; reuse of the envelope components; reuse of parts of the container's metal sheet.

The project uses the container as a structural resource. The employed module ensures high-structural performances, without introducing additional elements for the system stability (Bernardo et al. 2013).

We have studied operations to make this structure habitable. First, living space has been well conformed through the right aggregation of basic modules. Subsequently, the right functions have been included into the structure and the essential spatial characteristics have been applied. We followed the basic principle of maintaining a high degree of techno-typological and spatial flexibility for each space, while also guaranteeing the possibility of future extensions or changes in use.

\subsection{The Mock-Up}

The mock-up we are assembling is a 2-storey building. It consists of $4 \mathrm{HC} 40^{\prime}$, linked by an 'other space' made of a steel autonomous structure (Kotnik 2008; Kramer 2015). It will simulate different technical solutions and real-use conditions. It will be placed in eastern Milan suburbs (Fig. 2).

From a structural point of view, the main purpose is containing goods. Containers (Giriunas et al. 2012) have to provide a suitable resisting structure as well, so that no meaningful change in shape can occur under the effects of both weight and the different actions which may take place during the various phases of transportation and movement. Looking at the terminology, indeed, the term 'box' applies to the main function as well as the structural scheme. The main goal of the project is to limit additions to frames around the cuts and to avoid braces: for this reason, we have obtained the maximum hole the metal sheets are able to bear in normal and earthquake conditions in relation to buildings.

The foundation system is based on totally reversible screw poles, without concrete or other non-easily dismountable solutions. With respect to seismic protection, we 


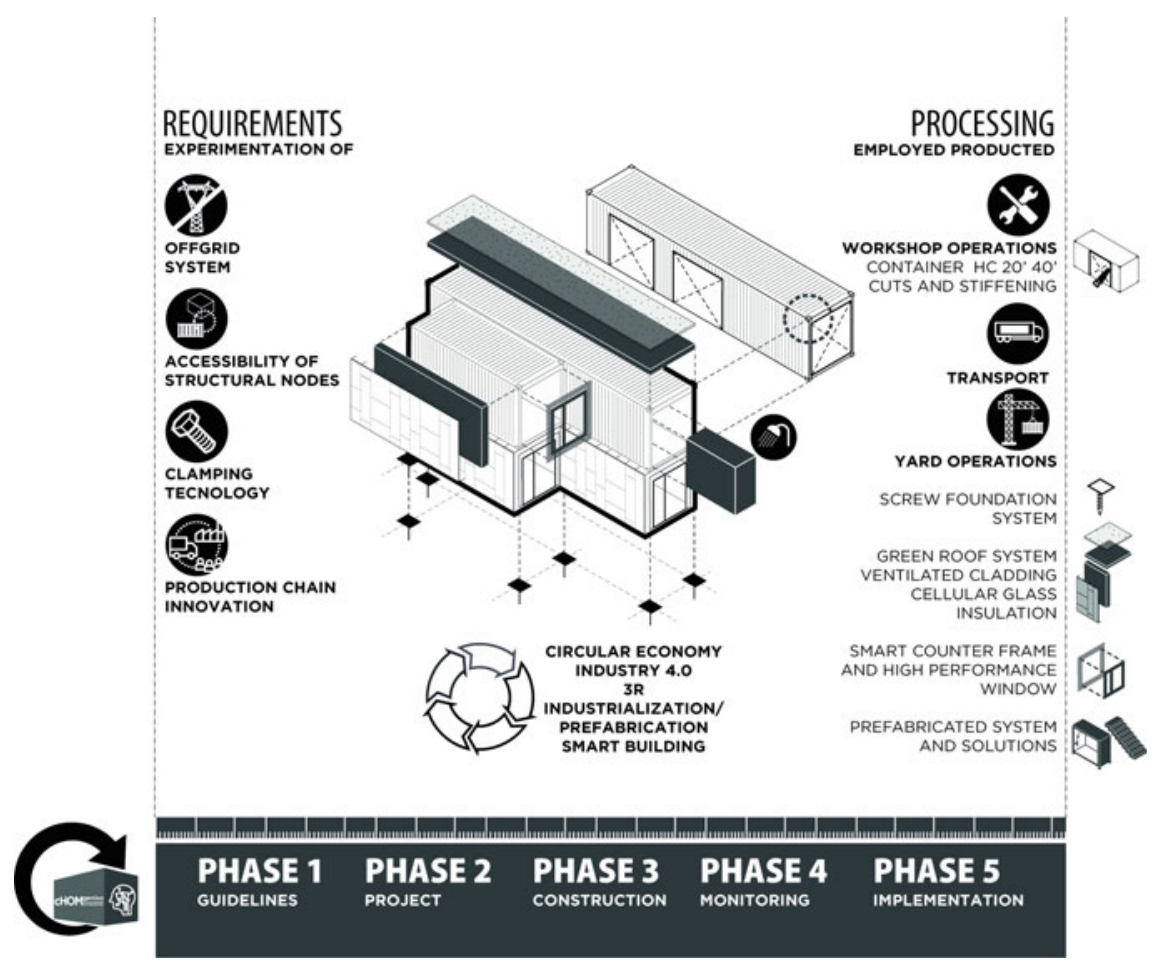

Fig. 2 Constructive scheme of the cHOMgenius mock-up

are developing a patentable device in which active sensors monitor the effects of horizontal forces and highlight possible damages; in addition, the seismic isolator is completely replaceable without uplifting the building.

Regarding the aggregation of modules, the boxes are jointed only at the corners and structural reinforcements are inserted only if an entire vertical sheet is cut away.

From the point of view of energy systems, the building is completely OFF-GRID thanks to a high-performance shell and $24 \mathrm{~V}$ electric plants that do not need converters. It is based on a bio-fuel cogenerator, linked with a $24 \mathrm{~V}$ heat pump, photovoltaic cells and a battery as storage (Fig. 3).

As regards the envelope, the containers are generally supplied without thermal insulation, and thus are not able to meet the energy performance requirements according to the legislation for NZEB buildings. The absence of a massive envelope also implies that buildings simply made up of containers have a low-thermal capacity. A change in the external temperature quickly leads to excessive cooling or overheating of the internal temperature with an extremely reduced delay time. Therefore, containers used for residential purposes require an insulation layer which must be placed outside the container, to avoid loss of internal surface and thermal bridges. For these reasons, we have considered cellular glass as the best material for such application: it is waterproof, able to stop the passage of steam, incombustible, resistant to harmful 
Fig. 3 Scheme of cHOMgenius energy plants

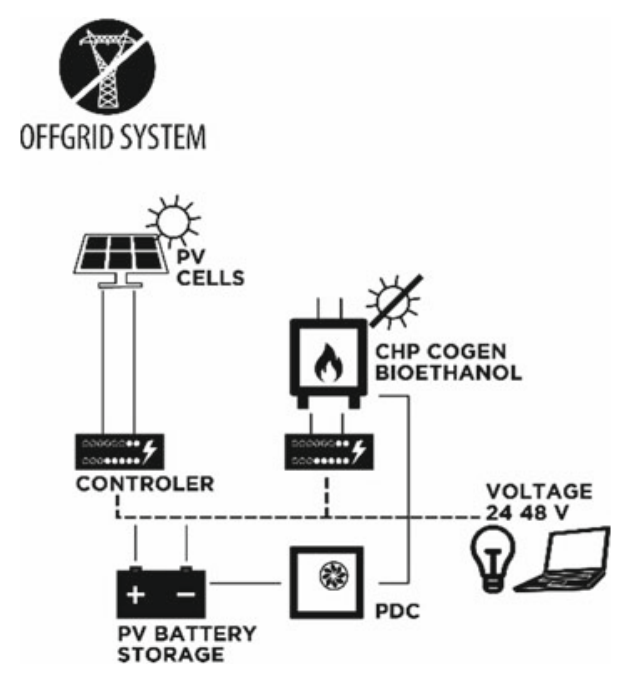

agents, acids and compression, non-deformable and easy to process. It is clamped to the sheet and sealed by removable adhesive.

\section{Conclusion: Potential and Future Developments}

Certainly, the proposal presents some weaknesses, but we have put forward possible solutions.

Firstly, the current normative apparatus based on traditional construction techniques is quite strict and not keen to recognize innovations. The difficulty to introduce the container system into the world of structural construction legislation could be solved through a structural safety assessment tool to validate the system in compliance with current legislation, as well as a tool for monitoring and reporting possible difficulties during use.

Another critical aspect is the need for an ad hoc design via technical, plant and structural solutions which are not available in current production. We have solved this problem by presenting innovative proposals to upgrade existing and consolidated products, according to the attainment of high performances combined with management and monitoring aspects, especially concerning anti-seismic and energetic/plant solutions.

The proposal may also present threats that could spoil the result. Among them, for example, a generalized vision linked to a negative perception of 'living in a container' with possible problems of acceptability. Such obstacle is easily overcome as the container is used as a structural system and, as far as permanent housing solutions are concerned, with guaranteed performances. Moreover, it is not visible unless the user chooses otherwise. 
One potentiality of this solution is the availability of containers as a second resource, offering facilitated handling, high availability and durability. In addition, the design strategies for the replicability of work in the workshop and on-site are the project's other advantages. The proposal could trigger the following opportunities: (a) the evolution of the construction sector in terms of energy, new trends related to performance requirements, forms of living space use, costs, turnover, technologies and construction techniques, products, components and systems, at national and international scale (by type and materials used); (b) the current period characterized by new cultural and operational environmental challenges, requiring a healthy competitive ability to meet differentiated needs with adequate, appropriate and timely responses; (c) the transition to Industry 4.0; (d) the need to reduce waste and the obligation to use resources consciously; (e) the growth of real-estate market for unconventional building solutions and the resilience of the certified high-performance housing market; (f) the possible regulatory evolution in terms of performance for buildings with incremental performances, advanced technical and innovative structural solutions and energy/environmental, functional, usability and maintainability levels; ( $g$ ) the harnessing of tax incentives in the field of energy self-consumption.

The sustainability of this system certainly depends on the environmental benefit of used materials, products and methods. However, it depends mostly on the ability to bind information through a multi-criteria structure, in order to produce benefits not individually, but rather as a system, from the perspective of an accomplished project.

\section{References}

Adalberth, K. (1997). Energy use during the life cycle of single-unit dwellings: Examples. Building and Environment, 32(4), 321-329.

Bernardo, L. F. A., Oliveira, L. A. P., Nepomuceno, M. C. S., \& Andrade, J. M. A. (2013). Use of refurbished shipping container for the construction of housing buildings: Details for the structural project. Journal of Civil Engineering and Management, 1-9.

Bologna, R. (a cura). (2002). La reversibilità del costruire. Rimini: Maggioli Editore.

Faludi, J., Lepech, M. D., \& Loisos, G. (2012). Using life cycle assessment methods to guide architectural decision-making for sustainable prefabricated modular buildings. Journal of Green Building, 7(3), 151-170.

Ginelli, E. (2010). La flessibilità tecno-tipologica nelle soluzioni progettuali e costruttive. In E. Bosio \& W. Sirtori (Eds.), Abitare. Il progetto della residenza sociale fra innovazione e tradizione. Santarcangelo di Romagna: Maggioli Editore.

Ginelli, E., \& Pozzi, G. (2017). Safety and energy controlled prefab building system. In Conference and proceedings of SGEM VIENNA GREEN 2017 (Vol. 17, Issue 63, pp. 503-510). ISBN 978619-7408-29-4/ISSN 1314-2704, 27-29 November 2017. https://doi.org/10.5593/sgem2017h/ 63/s26.064.

Giordano, R. (2010). I prodotti per l'edilizia sostenibile. La compatibilità ambientale dei materiali nel processo edilizio. Napoli: Esselibri S.p.A.: 243.

Giriunas, K., Sezen, H., \& Dupaix, R. B. (2012). Evaluation, modeling, and analysis of shipping container-building structures. Engineering Structures, 43, 48-57. 
Huanga, B., et al. (2018). Construction and demolition waste management in China through the 3R principle. Resources, Conservation and Recycling, 129, 36-44.

Islam, H., et al. (2016). Life cycle assessment of shipping container home: A sustainable construction. Energy and Buildings, 128, 673-685.

Jourda, F. H. (2010). Petit manuel de la conception durable. Paris: Archibooks + Sautereau.

Kotnik, J. (2008). Container architecture. Barcellona: Links.

Kramer, S. (2015). The box, architectural solution with container. Salenstein: Braun Editore.

Open Access This chapter is licensed under the terms of the Creative Commons Attribution 4.0 International License (http://creativecommons.org/licenses/by/4.0/), which permits use, sharing, adaptation, distribution and reproduction in any medium or format, as long as you give appropriate credit to the original author(s) and the source, provide a link to the Creative Commons license and indicate if changes were made.

The images or other third party material in this chapter are included in the chapter's Creative Commons license, unless indicated otherwise in a credit line to the material. If material is not included in the chapter's Creative Commons license and your intended use is not permitted by statutory regulation or exceeds the permitted use, you will need to obtain permission directly from the copyright holder.

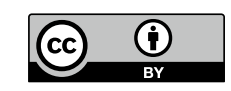

